\title{
DISCURSOS INCLUSIVOS EM CIRCULAÇÃO NAS ESCOLAS E SEUS EFEITOS NA AUTOCONDUÇÃO DOCENTE
}

\author{
INCLUSIVE DISCOURSES SPREAD AT SCHOOL AND THEIR EFFECTS ON TEACHER AUTOCONDUCTION
}

DISCURSOS INCLUSIVOS EM CIRCULACIÓN EM LAS ESCUELAS Y SUS EFECTOS EM LA AUTOCONDUCCIÓN DOCENTE

\author{
MENEZES, Eliana Pereira \\ TURCHIELLO, Priscila2
}

\begin{abstract}
RESUMO
Este artigo objetiva analisar os desdobramentos das políticas de inclusão na sociedade, problematizando os efeitos de tais políticas nos processos de subjetivação de docentes de escolas públicas. Ancoradas metodologicamente nos estudos foucaultianos, as análises ora apresentadas partem do trabalho em dois grupos de materiais: o primeiro constituído por discursos educacionais voltados para a educação inclusiva, produzidos no Brasil na última década; o segundo constituído por três investigações realizadas em escolas que possuem alunos em processos de inclusão. Nas análises foi possível perceber práticas discursivas produzidas pelos professores, cujos efeitos de subjetivação resultam na responsabilização da educação especial pela efetivação das ações inclusivas na escola e no silenciamento com relação as orientações políticas, o que acaba operando a não problematização e o fortalecimento do imperativo inclusivo no país.
\end{abstract}

Palavras-chave: Educação Inclusiva. Subjetivação. Educação Especial.

\section{ABSTRACT}

This paper aimed at investigating the unfolding of the inclusion policies in society, problematizing the effects of such policies on the processes of subjectivation of teachers in public schools. Methodologically grounded on Foucauldian studies, the analyses addressed two sets of materials: the first was composed of educational discourses directed towards inclusive education produced in Brazil along the last decade; the second included three investigations carried out in schools that had students undergoing inclusion processes. It was possible to notice that teachers produced discursive practices whose subjectivation effects both rendered special education responsible for accomplishing the inclusive action at school and silenced political guidelines, which in turn ended up operating the non-problematization and the strengthening of the inclusive imperative in Brazil.

Keywords: Inclusive Education. Subjectivation. Special Education.

\section{RESUMEN}

Este artículo tiene como intención analizar los desdoblamientos de las políticas de inclusión en la sociedad, problematizando los efectos de tales políticas en los procesos de subjetivación de docentes de escuelas públicas. Anclados metodológicamente en los estudios foucaultianos, los análisis presentados parten del trabajo en dos grupos de materiales: el primero, constituido por discursos educacionales volcados a la educación inclusiva, producidos en Brasil en la última década y el segundo constituido por tres investigaciones realizadas en escuelas que poseen alumnos en proceso de inclusión. En los análisis, fue posible percibir prácticas discursivas producidas por los profesores cuyos efectos de subjetivación resultan en la responsabilización de la educación especial por la efectivización de las acciones inclusivas en la escuela y en un silenciamiento con relación a las orientaciones políticas, que a su vez acaban operando la no-problematización y el fortalecimiento del imperativo inclusivo en el país.

Palabras clave: Educación Inclusiva. Subjetivación. Educación Especial.

\footnotetext{
1 Universidade Federal de Santa Maria - UFSM - Rio Grande do Sul - Brasil

2 Instituto Federal de Educação, Ciência e Tecnologia Farroupilha - IFFAR - Rio Grande do Sul - Brasil
} 


\section{CONTEXTUALIZAÇÕES INICIAIS SOBRE A TEMÁTICA}

Falamos em inclusão ${ }^{3}$ escolar no Brasil, pelo menos, desde o final dos anos 90 do século passado. Nesse tempo, muitas têm sido as pesquisas acadêmicas realizadas e as publicações resultantes das mesmas; os movimentos políticos apresentados pelo Governo; as mudanças de concepções dos sujeitos, direta ou indiretamente envolvidos com as práticas escolares, em relação a esse assunto; etc. Em meio a essa produção discursiva, pode parecer que a temática "inclusão escolar" esteja esgotada em seu potencial analítico. Entendemos que a depender do olhar direcionado a ela pode ser que realmente já a tenhamos analisado exaustivamente e, nesse contexto, não parece fazer mais sentido despender tempo com a produção de um artigo cuja intenção seja exatamente analisar os discursos inclusivos no Brasil.

No entanto, parece-nos ainda ser produtivo problematizar tal temática, especialmente porque não pretendemos no presente texto desenvolver uma defesa dos ideais inclusivos, discorrendo sobre suas benesses para a humanidade. Tampouco, pretendemos aqui produzir ajuizamentos de valor negativo com relação as práticas que têm sido desenvolvidas nas escolas, a partir das políticas inclusivas e, para tanto, apresentar uma série de dificuldades e obstáculos que têm se sobreposto à prática docente e que têm tornado questionável o nível de aproveitamento, em termos de aprendizagem, dos alunos ditos público alvo das ações inclusivas. O que pretendemos sim, é produzir uma problematização dos discursos inclusivos procurando discutir seus efeitos em termos de subjetivação docente, especialmente porque, no contexto deste texto, compreendemos tais discursos como um conjunto de práticas que operam a subjetivação dos indivíduos em busca de uma autocondução mais eficiente.

Considerando então, que esse conjunto de práticas de subjetivação é, como nos lembra Lopes (2009), uma invenção de nosso tempo, que não esteve desde sempre aí, como resultado da evolução humana, é que nos autorizamos a propor, nos moldes foucaultianos, a problematização que constitui o presente artigo. Ao fazer tal afirmação, parece-nos que já antecipamos nossa filiação teórica, ainda que ela vá ser mais detalhadamente apresentada na continuidade da discussão. Importa apenas ressaltar, que tal problematização é compreendida como um "[...] conjunto das práticas discursivas e não discursivas que faz alguma coisa entrar no jogo do verdadeiro e do falso e o constitui como objeto para o pensamento (seja sob a forma da reflexão moral, do conhecimento científico, da análise política, etc.)". (FOUCAULT, 2004, p. 242).

Nessa esteira, tomamos os discursos inclusivos como um conjunto de práticas produzidas neste mundo (como já afirmamos), que acabam conquistando status de verdade e, portanto, de necessários e indispensáveis para o desenvolvimento dos indivíduos e que, por isso tornam-se passíveis de serem pensados, pesquisados e analisados, como veremos na continuidade do texto.

\footnotetext{
3 O termo inclusão vem sendo significado, pelo grupo de pesquisa em que a presente investigação tem se desenvolvido, como um princípio do Estado que opera a mobilidade de todos os sujeitos em busca de sua autogestão, no entanto, no contexto do texto ora apresentado o termo inclusão foi trabalhado especificamente para designar práticas (discursivas e não discursivas) desenvolvidas no interior das escolas regulares para a efetivação do direito de ingresso e permanência dos alunos com deficiência nesses espaços.
} 


\section{CONTEXTUALIZAÇÕES METODOLÓGICAS E CONCEITUAIS SOBRE A PESQUISA}

As discussões analíticas, produtos da problematização com relação aos efeitos de subjetivação dos docentes, originam-se de um projeto de pesquisa (em andamento) cujo objetivo centra-se em investigar diferentes práticas discursivas no campo da educação especial, produzidas no contexto da racionalidade inclusiva. Tal investigação está sendo desenvolvida por um grupo de pesquisa vinculado ao CNPq e envolve pesquisadores da educação especial (inclusiva) de diferentes instituições de ensino superior do sul do país. A materialidade analítica da investigação é constituída a partir da eleição de práticas discursivas produzidas em diferentes âmbitos - produções acadêmicas, programas de Governo, documentos legais, produções midiáticas - que apresentam a educação especial de forma articulada a princípios de condução do Estado, dentro de uma racionalidade inclusiva ${ }^{4}$. Ao indicarmos tais materiais, optamos por organizar o percurso metodológico da pesquisa em três grupos de trabalho, guiados pela coleta e análise de diferentes materialidades:

$1^{\circ}$. Grupo: intenciona analisar a produção discursiva de trabalhos acadêmicos (relatórios de estágio, trabalhos de conclusão de curso, monografias, dissertações e teses) desenvolvidos na Universidade Federal de Santa Maria/UFSM, cuja temática esteja centrada na área da educação especial. A Universidade Federal de Santa Maria/RS constitui o foco dessa investigação por destacarse na produção de conhecimento em educação especial, sendo referência no país por oferecer desde 1962 formação na área. Atualmente, a instituição oferta três cursos de graduação em educação especial, sendo dois na modalidade presencial (diurno e noturno) e um na modalidade a distância, além de possuir uma linha de pesquisa em educação especial no seu Programa de Pós-Graduação em Educação.

$2^{\text {a }}$ Grupo: objetiva compreender como o Estado assume a discussão sobre as ações inclusivas e qual o lugar destinado à educação especial nessa discussão. Foram mapeadas as lógicas e as operações do serviço da educação especial na Contemporaneidade, e para isso propomos a análise de programas de Governo, documentos legais, materiais didáticos e de sensibilização que chegam às escolas no Brasil, como por exemplo, cartilhas, revistas, manuais e testes, pois entendemos que os discursos presentes nessas materialidades apresentam a educação especial de forma articulada a princípios de condução do Estado, dentro de uma racionalidade inclusiva.

$3^{\text {a }}$ Grupo: procura analisar os efeitos (em termos de subjetivação) dos discursos inclusivos nas práticas escolares desenvolvidas pelos professores de educação especial. Nessa etapa, ocupamo-nos da análise dos efeitos dos discursos nas práticas escolares, para tanto direcionamo-nos para escolas

\footnotetext{
${ }_{4}^{4}$ Por racionalidade inclusiva entendemos uma forma de vida posta em operação na Contemporaneidade, a partir da qual buscase a produção de subjetividades inclusivas (MENEZES, 2011) que possuam como imperativo a necessidade de ocuparem-se de si e dos outros para que todos possuam condições de inclusão/participação da vida em sociedade
} 
da rede pública de Santa Maria/RS, propondo a realização de entrevistas com educadoras especiais responsáveis pelo trabalho do AEE5.

Ancoradas metodologicamente nos estudos foucaultianos, as análises ora apresentadas partem do trabalho em materiais que constituem os primeiros dois grupos acima citados: documentos legais direcionados à educação inclusiva, produzidos no Brasil na última década; três investigações ${ }^{6}$ realizadas em escolas que possuem alunos em processos de inclusão, a partir das quais procurou-se entrevistar professores responsáveis pelo atendimento educacional especializado, além dos professores que constituem as equipes diretivas de tais espaços. Tais investigações foram desenvolvidas por três acadêmicas dos Cursos de Graduação em Educação Especial (diurno e noturno) e orientadas por professores da UFSM, em três escolas de três diferentes municípios do Estado do Rio Grande do Sul. Na realização das entrevistas, as questões elaboradas para a coleta dos dados centraram-se na organização e estruturação das ações inclusivas desenvolvidas pelas escolas; na efetivação de espaços de discussão e análise de tais ações e; na existência (ou não) de interlocução entre professores da educação especial e ensino regular no desenvolvimento das práticas ditas inclusivas.

Interessadas em empreender uma análise de discurso inspirada nos estudos foucaultianos, elegemos os excertos para compor a analítica deste texto a partir da busca por recorrências discursivas acerca da produção da educação especial enquanto campo de saber voltado a práticas inclusivas na escola; o atendimento educacional especializado enquanto serviço da educação especial que se volta ao desenvolvimento de ações específicas no contexto escolar inclusivo e; o lugar dos profissionais da educação especial nessa trama. Ao voltarmo-nos às recorrências dos materiais, elegendo como lentes teórico-metodológicas o pensamento do filósofo Michel Foucault, buscamos compreender os discursos como práticas que produzem a realidade, não apenas como um conjunto de signos - "um puro e simples entrecruzamento de coisas e de palavras" (FOUCAULT, 2008a, p.54) que representam os objetos. Para tanto, nossa atenção direciona-se para as possíveis relações em funcionamento nos discursos, que ao organizarem a realidade também produzem saberes, sendo os discursos tratados "como práticas que formam sistematicamente os objetos de que falam" (FOUCAULT, 2008a, p.55).

A opção pela filiação metodológica nos estudos foucaultianos - que resulta em uma compreensão diferenciada da construção metodológica de uma pesquisa, na qual as ferramentas de análise utilizadas não são escolhidas a priori, mas durante a construção do percurso metodológico conduziu-nos à identificação da utilidade e produtividade das ferramentas governamentalidade ${ }^{7} \mathrm{e}$ subjetivação ${ }^{8}$ para a análise dos efeitos em termos de subjetivação dos discursos inclusivos na

\footnotetext{
${ }^{5}$ Atendimento Educacional Especializado: forma atual de organização da prática em educação especial nas escolas regulares. Regulamentado pelo DECRETO № 7.611, DE 17 DE NOVEMBRO DE 2011, que dispõe sobre o atendimento educacional especializado e dá outras providências.

${ }^{6}$ Aqui identificadas como Pesquisa 1, Pesquisa 2 e Pesquisa 3 na apresentação e discussão dos fragmentos.

7 Significada como um estado permanente de governamento de si e dos outros.

${ }^{8}$ Ferramenta conceitual proposta por Foucault (1995) para compreendermos os modos pelo qual um ser humano sujeita-se a si mesmo e aos outros, "escolhendo" determinada forma de autocondução e não outras.
} 
condução docente, o que só se tornou possível a partir do momento em que passamos a olhar para os materiais que constituem a empiria deste estudo e que resultam nas discussões que serão apresentadas.

Entendemos, ainda, que antes de passarmos para a apresentação das discussões, de forma propriamente dita, faz-se importante pontuar que a produtividade visualizada pelo grupo de pesquisadores com relação as análises dos discursos inclusivos justifica-se pela compreensão de que tais discursos, ao mesmo tempo em que são produzidos a partir de uma razão de Estado, também são dela produtores. Ao serem produzidos, manifestam o governamento ${ }^{9}$ resultante das ações de governo e constituem-se como estratégias para a condução de demais sujeitos em direção a efetivação da escola para todos.

Em síntese, acreditamos que, com a presente investigação, podemos ver ações de governamento da população que resultam em ações que buscam o governamento de cada indivíduo dessa população (sendo operadas no interior das escolas) o que caracterizaria um estado permanente de governamento, ou, dito de outra forma, um estado governamentalizado ${ }^{10}$. Nesse processo de governamentalização da vida, segundo Foucault, o papel do sujeito é central. Passam por ele as práticas de condução de si e dos outros. É ele o personagem que, assumindo as verdades produzidas pela racionalidade de Governo em operação, mobilizar-se-á para que tais verdades sejam, também, assumidas pelos demais sujeitos.

Tal compreensão de sujeito, responsável por si e pelo outro, resulta dos estudos empreendidos pelo filósofo em questão, cujo objetivo principal, segundo ele próprio afirmou, "não foi analisar o fenômeno do poder nem elaborar os fundamentos de tal análise", mas sim "criar uma história dos diferentes modos pelos quais, em nossa cultura, os seres humanos tornaram-se sujeitos" (FOUCAULT, 1995, p. 231). Criar uma história dos modos de subjetivação que, conforme destaca Castro (2009, p. 408), são "precisamente, as práticas de constituição do sujeito".

A esse respeito, Castro (2009) considera que a expressão modos de subjetivação pode ser significada de duas formas na obra do filósofo. Uma primeira localiza o sujeito como objeto de relações de conhecimento e de poder. Seriam modos de subjetivação/objetivação que convertem os seres humanos em objetos de conhecimento, a partir de determinadas relações de poder que instituem jogos de verdade. Esses modos, segundo Foucault (1995, p. 231), podem ser distinguidos em três: "modo de investigação, que tenta atingir o estatuto de ciência"; práticas divisoras, nas quais "o sujeito é dividido no seu interior e em relação aos outros" e; o "modo pelo qual um ser humano torna-se sujeito".

E é em relação a esse último modo de subjetivação, que imprime ao indivíduo um trabalho consigo mesmo, que Castro (2009) localiza a segunda possibilidade de significação dos modos de subjetivação. Subjetivação pela sujeição a si mesmo, pela ação moral de si sobre si. Uma ação moral,

\footnotetext{
9 Governamento aqui entendido, conforme Veiga-Neto (2005), como a ação de condução de condutas.

${ }^{10}$ A constituição desse estado foi estudada por Foucault mais especificamente nos Cursos proferidos no Collège de France entre os anos 1970 e 1982. Dentre esses cursos, é em "Em defesa da sociedade" (1975-1976), "Segurança, território e população" (1977-1978), "Nascimento da biopolítica" (1978-1979) e "O governo dos vivos" (1979-1980) que, segundo Castro (2009), podemos perceber o início do predomínio das discussões sobre governo e governamentalidade.
} 
que não vai se distinguir das ações morais a que o sujeito é submetido nas relações (de poder) que estabelece com outros sujeitos e que o obrigam a assumir determinados comportamentos pela sujeição a determinadas verdades.

Nessa esteira, passaremos agora a uma discussão mais pontual da análise dos materiais trabalhados, a partir da qual foi possível perceber práticas discursivas produzidas (e assumidas) pelos docentes como verdades, cujos efeitos de subjetivação para as ações inclusivas resultam na responsabilização da educação especial com relação as práticas inclusivas, o que por sua vez acaba operando a não problematização e o fortalecimento do imperativo inclusivo no país. São discursos que subjetivam a todos os professores, afinal dificilmente encontramos aqueles que questionam a necessidade de operação de práticas inclusivas, mas há na escola alguns que são mais responsabilizados do que outros e esses, por sua vez, assumem como sua tal responsabilidade. Dessa forma, a maquinaria de governo permanece em funcionamento.

\section{DISCURSOS INCLUSIVOS E PRÁTICAS ESCOLARES: EFEITOS NA CONDUÇÃO DOCENTE}

Ao iniciarmos esta seção do trabalho, trazemos Menezes (2011) para pontuar que os movimentos (políticos, educacionais, sociais) produzidos nas últimas décadas no país, acabaram instituindo a inclusão escolar - inicialmente entendida como uma possibilidade - como uma prática obrigatória e não-questionável. Ainda, segundo a autora, "na Contemporaneidade, a agenda política educacional não encontra espaços para discutir ou relativizar a obrigatoriedade da inclusão escolar" (MENEZES, 2011, p. 50). Ao partirmos dessa afirmação, não temos a intenção, como já afirmamos anteriormente, de julgar as práticas inclusivas como práticas desnecessárias ou prejudiciais ao contexto educacional e social. O que propomos ao utilizá-la, é indicar que se faz importante analisar a produção da trama discursiva que tem instituído verdades sobre a inclusão, produzindo-a como uma necessidade nas práticas escolares, em caráter imperativo para todos os sujeitos, independente das condições pedagógicas existentes para tal fim. Parece-nos que o não tensionamento da inclusão como uma verdade pode ser, como lembra-nos Foucault, perigoso. "[...] o que há, enfim, de tão perigoso no fato de as pessoas falarem e de seus discursos proliferarem indefinidamente? Onde, afinal, está o perigo?" (FOUCAULT, 2000, p. 08). No contexto da presente discussão, o "perigo" está no poder circulante nas tramas discursivas, que institui subjetividades, determina padrões de comportamento, classifica os sujeitos, produzindo efeitos de in/exclusão na escola.

Ao propormos essa análise, filiamo-nos a Ó quando afirma que "é sempre um problema de linguagem que se encontra na origem e na constituição do mundo" (Ó, 2009, p. 25) e, portanto, na constituição das práticas. Assim, ao analisar a produção de discursos inclusivos, tomamos a linguagem naquilo que ela tem de produtivo para entender como, por práticas de subjetivação, fomos sendo produzidos como sujeitos convencidos a olhar para a inclusão de forma naturalizada, sem questionar motivos, intenções e efeitos dessa política. O lugar central que a linguagem ocupa no contexto teórico em que esse estudo está sendo produzido justifica-se pelo caráter atributivo que é dado à linguagem.

Nessa esteira, a partir dos estudos foucaultianos entendemos que ao falarmos sobre alguma coisa ou alguém, estamos empreendendo sempre um exercício de poder. 
Quem fala acaba por instituir formas de olhar para aquilo e/ou aquele sobre quem fala, ou seja, a significação das pessoas e das coisas que constituem a cultura não se dá de forma natural, sendo social e culturalmente produzida. Portanto, produzimos pela linguagem aquilo sobre o que falamos, de maneiras variadas, em significados que não são únicos; ao fazer isso, privilegiamos ou excluímos determinados significados em detrimento de outros. (MENEZES, 2011, p.50).

Assim, compreendendo que a linguagem não apenas representa a realidade ${ }^{11}$ mas, principalmente, a produz, é que procuramos nos ocupar das formulações discursivas acerca da inclusão escolar no país, afinal, tais formulações discursivas acabarão por determinar a realização de práticas que colocam o discurso em funcionamento, operando para a produção de determinados efeitos desejados.

Conforme já havíamos sinalizado, desde a década de 90 temos visto investimentos do Governo brasileiro na produção de políticas inclusivas com a intenção de "ressignificar' o ideário social e educacional acerca das pessoas com deficiência" (TURCHIELLO, 2009, p.49). Nesse terreno, o presente texto busca olhar para os discursos educacionais inclusivos dando visibilidade às práticas operadas na subjetivação de docentes, que assim como outros grupos de sujeitos e instituições, têm sido chamados a responsabilizarem-se pela condução das condutas das pessoas com deficiência.

A publicação da LDB 9.394/96 no final do século XX ganha destaque em relação a organização de um capítulo inteiro voltado a orientações e ações que dizem respeito à educação de pessoas com deficiência. Pautados nessa legislação, diversos documentos legais foram elaborados no Brasil buscando condições de efetivação da escola inclusiva. Tais documentos, são publicados assegurando a educação básica para os alunos com deficiência, entendendo que a reestruturação das escolas para o desenvolvimento do projeto inclusivo constitui-se como possibilidade para que práticas segregadoras sejam superadas no sistema de ensino brasileiro. Nessa esteira, ao posicionar a educação especial como área de saber que realizará o apoio, complementação e suplementação dos serviços educacionais prestados pelas escolas regulares, esses documentos produzem-na como uma das áreas responsáveis pela criação de condições de permanência dos alunos com deficiência na escola, mas não a única.

A escola comum se torna inclusiva quando reconhece as diferenças dos alunos diante do processo educativo e busca a participação e o progresso de todos, adotando novas práticas pedagógicas. Não é fácil e imediata a adoção dessas novas práticas, pois ela depende de mudanças que vão além da escola e da sala de aula. Para que essa escola possa se concretizar, é patente a necessidade de atualização e desenvolvimento de novos conceitos, assim como a redefinição e a aplicação de alternativas e práticas pedagógicas e educacionais compatíveis com a inclusão (Brasil, 2010, p. 09).

Um ensino para todos os alunos há que se distinguir pela sua qualidade. O desafio de fazê-lo acontecer nas salas de aulas é uma tarefa a ser assumida por todos os que compõem um sistema educacional. Um ensino de qualidade provém de iniciativas que envolvem professores, gestores, especialistas, pais e alunos e outros profissionais que compõem uma rede educacional em torno de uma proposta que é comum a todas as escolas e que, ao mesmo tempo, é construída por cada uma delas, segundo as suas peculiaridades. (Brasil, 2010, p. 10).

\footnotetext{
11 Realidade aqui compreendida como uma dentre as muitas possibilidades que temos de interpretar uma mesma materialidade.
} 
A partir de tais fragmentos, identificamos que é na aposta da parceria entre professor do ensino regular, professor de educação especial e demais sujeitos que constituem as escolas, que os discursos oficiais localizam as melhores possibilidades de efetivação das ações inclusivas. No entanto, parecenos que ao delegar à educação especial grande parte das responsabilidades na organização, planejamento e execução dos serviços, tais discursos, ao serem assumidos pelos professores, acabam significando a educação especial como a principal (ou única) responsável pela inclusão dos alunos que possuem deficiência, cabendo aos demais professores apenas a efetivação da matrícula e a tolerância da presença desse aluno na sala de aula.

[...] a inclusão está diretamente ligada à educação especial sendo que, é responsabilidade deste campo de saber dar conta desse alunado. Parece que não se tem a intenção nesta escola de trabalhar para que este aluno seja incluído nas suas práticas pedagógicas, pois sabe-se que ele poderá retornar à escola especial caso não se adapte ao espaço regular assim que a idade obrigatória de escolarização seja superada (Pesquisa 2).

[...] se os alunos da escola inclusiva são os alunos com deficiências, então há a educação especial para se responsabilizar por eles (Pesquisa 3).

A educação especial está presente em boa parte das discussões referentes às políticas inclusivas que tem se resumido a alunos com deficiências. E, quando pensamos nestes indivíduos, imediatamente pensamos em Educação Especial, com isso, acabamos por responsabilizar a Educação Especial como os únicos protagonistas da inclusão (Pesquisa 2).

Embora a elaboração do projeto político pedagógico para uma escola inclusiva seja de responsabilidade de todos os envolvidos com o processo educativo, fica evidente que é a educadora especial que tem conduzido esse processo, bem como, está sendo responsabilizada por essas discussões referentes à inclusão na escola. (Pesquisa 3).

Durante o ano de 2007, época do segundo mandato do Presidente Luiz Inácio Lula da Silva, o Ministério da Educação apresenta o Plano de Desenvolvimento da Educação. Esse documento demonstra a intensificação de propostas que marcaram a última década no que se refere às políticas de inclusão, posicionadas como aquelas que possibilitariam a construção de um ideário educacional em que não haja oposição entre educação regular e educação especial.

[...] o fortalecimento dos discursos inclusivos alinha-se, mais uma vez, a um movimento global que posiciona a inclusão como um direito a ser garantido em diferentes contextos (na família, na sociedade, na escola, no trabalho, etc.), buscando promover condições de igualdade para a população com deficiência. (TURCHIELLO, 2017, p.147).

Com a finalidade de definir o lugar da educação especial e organizar as práticas inclusivas no espaço da escola regular, foram apresentados nos últimos anos o Decreto № 6.571 , de 17 de setembro de 2008, que dispõe sobre o atendimento educacional especializado, sendo esse documento revogado pelo Decreto No 7.611, de 17 de novembro de 2011 (no governo da Presidenta Dilma Rousseff) e a Resolução $N^{\circ}$ 4, de 02 de outubro de 2009, que institui diretrizes operacionais para o atendimento educacional especializado na educação básica, modalidade educação especial. Neles fica estabelecido que:

Art. 2o A educação especial deve garantir os serviços de apoio especializado voltado a eliminar as barreiras que possam obstruir o processo 
de escolarização de estudantes com deficiência, transtornos globais do desenvolvimento e altas habilidades ou superdotação.

$\S 1$ - Para fins deste Decreto, os serviços de que trata o caput serão denominados atendimento educacional especializado, compreendido como o conjunto de atividades, recursos de acessibilidade e pedagógicos organizados institucional e continuamente, prestado das seguintes formas:

I - complementar à formação dos estudantes com deficiência, transtornos globais do desenvolvimento, como apoio permanente e limitado no tempo e na frequência dos estudantes às salas de recursos multifuncionais; ou

II - suplementar à formação de estudantes com altas habilidades ou superdotação.

$\S 2 \circ O$ atendimento educacional especializado deve integrar a proposta pedagógica da escola, envolver a participação da família para garantir pleno acesso e participação dos estudantes, atender às necessidades específicas das pessoas público-alvo da educação especial, e ser realizado em articulação com as demais políticas públicas (BRASIL, 2011, p.1-2).

Nessa lógica, a implantação do atendimento educacional especializado nas escolas regulares configura a atuação da educação especial na provisão de recursos e serviços para promover a permanência dos alunos com deficiência nos bancos escolares, mantendo-os sob controle. "Com outras roupagens, a educação inclusiva traz a educação especial para dentro da escola regular e a responsabiliza pela realização das ações de implementação, desenvolvimento e acompanhamento das ações relativas à educação inclusiva" (MENEZES, 2011, p.57). Consideramos ainda, de acordo com Turchiello (2017), que a educação especial acaba por ocupar-se de criar as condições para a permanência dos estudantes com deficiência nos espaços comuns, voltando-se para a potencialização das aprendizagens dos sujeitos ditos incluídos.

Para a institucionalização do atendimento educacional especializado, as escolas precisam prever em seus projetos pedagógicos a organização da sala de recursos multifuncionais, a realização da matrícula dos alunos no AEE, a organização de cronogramas de atendimentos e do plano de AEE, bem como prover o professor para o AEE e outros profissionais da educação que se façam necessários, buscando, ainda, a articulação com redes de apoio. A partir da previsão de um professor responsável pelo atendimento educacional especializado, assim como por boa parte das ações em torno da efetivação da inclusão de alunos com deficiência nas escolas regulares, entendemos que são colocadas em funcionamento práticas de subjetivação docente, já que temos, orientações para o desenvolvimento do AEE, que buscam por práticas de subjetivação, conduzir as condutas dos diferentes atores convocados a atuar na chamada 'comunidade escolar', para a efetivação da escola para todos.

[...] as respostas apresentadas pelos sujeitos da investigação foram fiéis às orientações políticas que são apresentadas como diretrizes para implantação do AEE. Diante disso, é possível analisar que tais orientações estão sendo recebidas pelas escolas e pelos professores do AEE como normas, como normativas que não podem ser questionadas (Pesquisa 1).

[...] fica visível o fato de que as professoras participantes da pesquisa tomam as orientações apresentadas pelos documentos legais como verdades impassíveis de reflexões, mesmo sendo possível perceber através dos diálogos que existem algumas insatisfações (Pesquisa 2). 
[...] ao mesmo tempo em que existem estas insatisfações, existe também uma imobilidade por parte dos sujeitos envolvidos com relação à naturalização da falta de condições presentes nas escolas para que as práticas sejam mais qualitativas. (Pesquisa 2).

Consideramos interessante problematizar o fato de que apesar dos discursos inclusivos terem sido assumidos como verdades (e, portanto, como uma necessidade), esteja recaindo sobre a educação especial as principais obrigações para sua efetivação nas escolas. O que nos parece curioso é que, se tais discursos têm subjetivado a todos os professores - o que é possível ser visualizado exatamente pela já anunciada ausência de espaços de problematização dessa política educacional nas escolas - não deveríamos encontrar discursos que demonstram como cada professor tem se mobilizado para que a inclusão aconteça? Será que as estratégias discursivas utilizadas para operar tal mobilização não estão sendo tão potentes quanto necessárias? E, por sua vez, será que as ênfases feitas nos documentos produzidos pelo Governo quanto as ações da educação especial nesse processo não estão sendo totalizantes em demasia? Ao materializar-se dessa forma, não podemos concluir que ao fim e ao cabo estamos tratando de um projeto de Governo que é produzido como uma ação de todos (e para todos), mas que acaba sendo uma ação de alguns (e para alguns)?

Conforme a Política Nacional de Educação Especial na perspectiva da educação inclusiva (2008) o "movimento mundial pela educação inclusiva é uma ação política, cultural, social e pedagógica, desencadeada em defesa do direito de todos os alunos de estarem juntos, aprendendo e participando, sem nenhum tipo de discriminação" (BRASIL, 2008, p.1). Entendemos que tal afirmação, ao amarrar as ações inclusivas a uma questão de direitos humanos, localiza a inclusão escolar como prática indispensável para o desenvolvimento social do país e opera práticas de subjetivação docente para a não problematização das ações inclusivas. Os discursos que localizam a educação especial como responsável pela oferta de atendimento educacional especializado e mobilizadora de práticas inclusivas, acabam por reafirmar a posição central da educação para viabilizar os projetos sociais e potencializar o desenvolvimento do país (TURCHIELLO, 2017).

[...] a não problematização é um efeito de uma inclusão que está naturalizada. Ou seja, parece
que o discurso é "temos que incluir os alunos, pois existe um movimento a favor da inclusão, e
ela deve ser implantada na escola, pois a escola é para todos" e dessa forma as ações vão
sendo desenvolvidas sem criteriosidade, e assim produzem efeitos que nem sempre são efeitos
de inclusão do aluno com deficiência na escola, mas também efeitos de exclusão (Pesquisa 2).
[...] a inclusão escolar vem sendo implementada exatamente como as políticas recomendam,
como as políticas "ensinam" a fazer. Sem que assim haja condições e espaços para que sejam
contestadas as condições para efetivá-la (Pesquisa 3).

A inclusão, tomada como um imperativo, acaba por operar práticas educacionais e sociais consideradas "uma potente estratégia para a democratização da sociedade, na qual princípios como justiça, igualdade, direitos e liberdades sejam garantidos a todos" (TURCHIELLO, 2017, p.123). Diante disso, considera-se, também, que a inclusão acaba funcionando enquanto argumento "para o convencimento de que sua efetivação permite a eliminação de práticas de exclusão" (TURCHIELLO, 2017, p.123-124).

Dessa maneira, pensamos que se a inclusão escolar é uma questão de direitos humanos, poucos sentem-se à vontade para questioná-la, e assim não questionamos as práticas que têm sido 
desenvolvidas e, tampouco, os efeitos em termos de aprendizagem dos alunos. Nessa lógica, entendemos ser possível afirmar que os discursos inclusivos têm produzido efeitos de subjetivação de docentes de escolas públicas que resultam na realização de práticas em espaços específicos de atendimento do aluno com deficiência, localizados dentro do contexto escolar. Todos assumem a importância da operacionalização dos espaços inclusivos, tanto na escola quanto na sociedade, mas a necessidade de mobilização para que eles se efetivem é delegada com mais potência a alguns sujeitos. Esses por sua vez, ao não manifestarem sua inconformidade com a forma como são responsabilizados (pelos sucessos e pelos fracassos), acabam enfraquecendo-se politicamente e anulando qualquer possibilidade de resistência e/ou negociação existente.

\section{POSSÍVEIS CONSIDERAÇÕES PARA A FINALIZAÇÃO DA PRESENTE DISCUSSÃO}

A leitura que se tornou possível, a partir da análise da materialidade eleita para compor esse texto, permite-nos considerar que são operadas práticas que demarcam a educação especial como campo de saber destinado a busca pela inclusão escolar dos alunos com deficiência na escola comum. Todos, de alguma forma, sentem-se convocados a desempenhar papéis que potencializem a inclusão, no entanto, a responsabilidade mantém-se a cargo daqueles profissionais que assumem o atendimento educacional especializado. Nessa lógica, as escolas passam a ser consideradas, muitas vezes, como espaços inclusivos quando disponibilizam de sala de recursos multifuncionais e profissionais da educação especial, esmaecendo, conforme já afirmamos, as possibilidades de problematização sobre a inclusão e seus efeitos na escolarização das pessoas com deficiência.

Em relação à atuação dos profissionais da educação especial, podemos perceber que ao não questionarem os preceitos legais e tomarem as orientações políticas como diretrizes, uma espécie de cartilha, acabam por restringir o campo de saber da educação especial à utilização de recursos e métodos que por si só garantiriam a inclusão dos alunos com deficiência. Com isso, reforçam-se os discursos que produzem os sujeitos em processos de inclusão como sujeitos da falta, não aprendentes, cujas práticas de normalização - operadas pela educação especial - fazem-se necessárias para que possam estar incluídos na escola.

Assim, ao concluir a presente discussão, consideramos que as análises aqui produzidas podem constituir-se como possibilidades de resistência ao leitor que, assim como nós, estiver insatisfeito com as evidências apresentadas. "E resistir faz-se importante, entre outras coisas, porque, como nos lembra Larrosa (2002), a resistência resulta da percepção de que 'as evidências são também fabricadas"' (MENEZES, 2011, p.178) e que o nosso olhar é mais livre do que pensamos. Logo, se o que nos constitui como sujeitos pode não ser tão inquestionável e revogável quanto pensamos, parecenos ser importante autorizarmo-nos a questionar as tramas que nos subjetivam, enquanto docentes, a produzir práticas escolares ditas inclusivas, sem criteriosidade, para, a partir desses questionamentos e problematizações, procurar pelo estabelecimento de espaços de análise e compreensão do que temos produzido dentro das escolas e dos seus efeitos em termos de condução de condutas dos alunos nomeados como deficientes, assim como dos professores e alunos com eles envolvidos. 


\section{REFERÊNCIAS}

1. BRASIL. A Educação Especial na Perspectiva da Inclusão Escolar: a escola comum inclusiva. Brasília: Ministério da Educação, Secretaria de Educação Especial, 2010.

2. BRASIL. Política Nacional de Educação Especial na Perspectiva da Educação Inclusiva. Brasília, 07 jan. 2008.

3. BRASIL. Lei de Diretrizes e Bases da Educação Nacional. Lei n. 9394/96, de 20 de dezembro de 1996. Estabelece as diretrizes e bases da educação nacional. São Paulo: Brasil, 1996.

4. CASTRO, Edgardo Manuel. Vocabulário de Foucault: Um percurso pelos seus temas, conceitos e autores. Belo Horizonte: Autêntica, 2009.

5. FOUCAULT, Michel. Do governo dos vivos: curso no Collége de France, 1979-1980 (excertos). São Paulo: Centro de Cultura Social; Rio de Janeiro: Achiamé, 2010.

6. FOUCAULT, Michel. Arqueologia do saber. Tradução Luiz Felipe Baeta Neves. 7. ed. Rio de Janeiro: Forense Universitária, 2008a.

7. FOUCAULT, Michel. Segurança, Território e População. São Paulo: Martins Fontes, 2008b.

8. FOUCAULT, Michel. Nascimento da Biopolítica. São Paulo: Martins Fontes, 2008c.

9. FOUCAULT, Michel. Em defesa da Sociedade. São Paulo: Martins Fontes, 2005.

10. FOUCAULT, Michel. O cuidado com a verdade. In: FOUCAULT, Michel. Ditos\&Escrito: Ética, sexualidade, política. Rio de Janeiro: Forense Universitária, 2004. p. 240-251. v.5.

11. FOUCAULT, Michel. A ordem do discurso. São Paulo: Loyola, 2000

12. FOUCAULT, Michel. O Sujeito e o Poder. In: DREYFUS, Hubert L; RABINOW, Paul. Michel Foucault. Uma Trajetória Filosófica: para além do estruturalismo e da hermenêutica. Rio de Janeiro: Forense Universitária, 1995. p. 231-249. 
13. LOPES, Maura Corcini. Inclusão como prática política de governamentalidade. In: LOPES, Maura Corcini; HATTGE, Morgana Domênica (Orgs.). Inclusão Escolar: conjunto de práticas que governam. Belo Horizonte: Autêntica, 2009. p. 107-130.

14. MENEZES, Eliana da Costa Pereira de. A maquinaria escolar na produção de subjetividades para uma sociedade inclusiva. 2011. 189f. Tese (Doutorado em Educação) - UNISINOS, São Leopoldo.

15. Ó, Jorge Ramos do. A "criança problema e o seu governo em Portugal e no Brasil (1880-1960): discursos e práticas. In: Ó, Jorge Ramos do; CARVALHO, Luís Miguel. Emergência e circulação do conhecimento psicopedagógico moderno (1880-1960): estudos comparados Portugal - Brasil. Lisboa: UI\&DCE, 2009. p. 09-153.

16. TURCHIELLO, Priscila. A produtividade dos sujeitos com deficiência na articulação da educação profissional e tecnológica com a inclusão. 2017. 228 f. Tese (Doutorado em Educação) - UFSM, Santa Maria.

17. TURCHIELLO, Priscila. A hora e a vez da família em uma sociedade inclusiva: problematizando discursos oficiais. 2009. 83f. Dissertação (Mestrado em Educação) - UFSM, Santa Maria.

18. VEIGA-NETO, Alfredo. Coisas do governo...In: RAGO, Margareth; ORLANDI, Luiz B. Lacerda; VEIGA-NETO, Alfredo. Imagens de Foucault e Deleuze: ressonâncias nietzschianas. Rio de Janeiro: DP\&A Editora, 2005. p. 13-34.

\section{Eliana Pereira Menezes}

Professora Adjunta do Departamento de Educação Especial da Universidade Federal de Santa Maria Priscila Turchiello

Docente de Educação Básica, Técnica e Tecnológica na área de Educação Especial/AEE no Instituto Federal de Educação, Ciência e Tecnologia Farroupilha - Campus Jaguari

\section{Como citar este documento}

MENEZES, Eliana Pereira; TURCHIELLO, Priscila. Discursos inclusivos em circulação nas escolas e seus efeitos na condução docente. Reflexão e Ação, Santa Cruz do Sul, v. 28, n. 1, jan. 2020. ISSN 1982-9949. Disponível em: <https://online.unisc.br/seer/index.php/reflex/article/view/11748>. Acesso em: doi:https://doi.org/10.17058/rea.v28i1.11748. 